\title{
An Adaptive Man: Hardiness Resources In the Conditions of System Crises at the Turn of the XIX-XX and the XX- XXI Centuries
}

\author{
Nadezhda V. Lipatova \\ Ulyanovsk State University, 432017, Ulyanovsk, Russia, Institute of Historical and Cultural Research of the Ulyanovsk Region \\ Ulyanovsk, 432063, Ulyanovsk, Russia \\ Email: nlipatova@mail.ru \\ Valentina B. Salakhova \\ Tatyana A. Chertushkina \\ Svetlana V. Ermolayeva \\ Irina V. Mikhaylova \\ Olga Yu. Shrol \\ Sergey V. Panteleev
}

Ulyanovsk State University, 432017, Ulyanovsk, Russian

\section{Doi:10.5901/mjss.2015.v6n2s3p136}

\section{Abstract}

Importance of the studied problem is caused by the need of investigating a prompt and many-sided transformation of the personality in the conditions of the crisis era. Globalization and a mass scale migration process that provoked interaction of norms of traditional and information societies. The purpose of the article is a complex retrospective analysis of ecological and biological, social and psychological indicators of the personality's hardiness in the context of society transformation at the turn of the XIX-XX centuries and the $X X-X X I$ centuries in the conditions of the Post-Soviet transition. Such cross-disciplinary analysis of psychology, history, cultural anthropology, pedagogics, ecology - gives an opportunity to develop algorithms of increasing efficiency of the human capital and to increase quality of health improving technologies and mechanisms of increasing the personality's hardiness. The leading approach in research of such complicated process is a complex retrospective analysis on the basis of interdisciplinary and integrative approaches. It is such approach to a research problem that has been realized in this article. The result of it is systematization of ecological and biological, social and psychological hardiness markers of the individual in the conditions of society transformation; the analysis of components of social competence of the personality at the personal and behavioural levels and major factors of adaptation of the personality in the conditions of the catching-up development of Russian society, and also psychological, traditional and historical and ecological aspects of the person's development in the conditions of a crisis era on an example. Materials of the article can be useful for working out adaptation technologies and techniques for migrants, for work in the social and educational sphere, in the centers of psychological assistance. It is possible to develop the content of the expert system on the basis of the designated criteria in the long term.

Keywords: psychological characteristics of the past; historical psychology; society transformation; mentality; ecology of the man; hardiness of the personality, personal potential; expert analytical model; cultural practices; social structural crises.

\section{Introduction}

Modern crisis era combines systemacity and designing of traditions which often are a mixture of former and new meanings (Hobsbawm, 1983). An interdisciplinary approach is required for its studying. In particular only from these positions, it is possible to trace transformation of the person's adaptation abilities in a crisis era in a historical retrospective (Toffler, 2002) on condition of an internal contradiction in interpretation and understanding of traditions. Mental human life represents the unity in which the scientific analysis distinguishes such separate parts as mental processes, states, relations and properties of the personality where the personality is characterized, first of all, by the 
system of the man's relations to the external world and to himself (Myasishchev, 1960). Studying the interaction of the person with the ecological and social environment in the conditions of society transformation and social transition is the practice-oriented problem of modern Russian society. The behavior of the person, his strategy and dependence on the environment in the conditions of transition from traditional to industrial and to information society is based further on the set of spontaneously arising ideas about the environment and the person's abilities which are formed by the dominating tradition and the existing knowledge. Collision of these ideas with the accelerated process of changes causes an imbalance of the personality and decrease in its hardiness and social activity. Static measurement of society was studied by Russian and foreign researchers to some extent. However models of the personality's transformation in the context of change of historical, social, ecological conditions, their dynamics and the internal logic of change of the person's identification markers with the environment have not been developed completely. Forecasting and expert assessment of change of the personality in the conditions of society transformation and structural crisis of the society by means of a mathematical model will allow a competent scientific community to trace more deeply the processes of transformation of the personality in the conditions of system crises. Identifying markers of the transitional type of the personality (from Soviet to Post-Soviet and from traditional agrarian to industrial) will allow us to rethink and to trace the system change of the personality in the conditions of transition taking into account ecological, social, psychological changes in the society.

This article is an attempt to find reference points in the past and the present and to reveal traditionally working mechanisms of adaptation of the man permitting him to cope successfully with a crisis situation, and also to trace real changes of the environment influence for 100 years, to compare them with ecological measurements and data of anthropometrical measurements. In the long term it is possible on the basis of the designated criteria to develop the content of the expert system (Jackson, 2001) regarding the issues of formation, development and forecasting of the interaction process of ecological and biological, social and psychological factors for forecasting the the personality's hardiness in the conditions of society transformation (Milov, 1992).

\section{Methodological Framework}

\subsection{World outlook contradictions of a crisis era}

The modern person faces contradictions and difficulties which are almost not solvable and require a new solution every second. Understanding the world, outlook of the person is a substantial component of human culture. Each cultural person needs to picture to himself at least in general how the world in which he lives is arranged how laws of the nature "function" in it. Richard Tarnas (1991) in the book "Passion of Western Mind" describes the essence of contradictions by means of the situation of "double knot", the phrase had been introduced into scientific circulation by Bateson (1972). He uses this term to describe the situation of dependence of the child on his mother (Richard, 1991). Tarnas replaces the word "mother" with the word "world" in this formula of "double knot", and the word "child" with the word "person", recreating a picture of "double knot" of modern reality, in which there are four main postulates: 1 ) the relation of the person to the world is the vital dependence therefore it is extremely important to estimate precisely messages from outside; 2) the human intelligence receives inconsistent information from the world; 3 ) from an epistemological position, the human intelligence is not capable of establishing direct communication with the world; 4) in existential sense, the person can not "drop out of the game" (Bateson, 1972).

The Russian modern reality is supplemented also by the catching-up factors of the society development. Nature of the accelerated and catching up development of the country became almost canonical for the historiographic tradition (Shpet, 1989). Such look undervalues and disparages many aspects of life of Russia not only in the pre-Petrine era, but also at the beginning of the XX century. However it is necessary to consider that these views have a strong emotional and psychological support by means of creating an image of Russia which is incessantly lagging behind and compelled to catch up with other world (Shapovalov, 2003). Professor V. F. Shapovalov considers that breaks of social memory are not rare in the history, and from culture its whole layers can drop out making up a major part of the previous cultural era until recently. And this discontinuity of development is changing the understanding of transformation and succession. When we speak about traditions and succession, semantic content of these traditions can be various. However the current state of technological acceleration raises a question not so much of a break, but of the transformation of ideas and the internal conflict of images and ideas. We will designate the three spheres in which the man had to face changes for 100 years. This is, first of all, hardiness which accumulates all changes, the environment changes which made the person change together with it and transformation of traditions as such. 


\subsection{Hardiness and its criteria}

The concept "hardiness", introduced by Susan Kobeysa and Salvatore Maddi, expresses individual abilities of the personality for mature and complex forms of self-control both on existential, and on the psycho-physiological level of the person's functioning (Maddi, 1994). In an existential sense hardiness corresponds to the concepts of courage (P. Tillikh, 1995), existential courage (R. Mai, 2001), readiness to act contrary to any haphazard and arbitrary actions (M. Heidegger, 1960), authorship of life (V. Frankl, 1990; I. Yal, 1999). The psycho-physiological aspect of hardiness is characterized by that role which these features play in the destructive influence minimization of stress-producing factors on a human body.

In the structure of hardiness three interconnected mental sets are distinguished: the involvement, control and acceptance of risk, determining ability of the personality to transform negative impressions to new opportunities and to resist the destructive influence of stress-producing factors on somatic health and sanity, and also on success of activity. Most researchers agree to the opinion that hardiness in many respects is determined by the fact what foundation of values will be created in the younger generation (A. Maslou, 1968; V. Frankl, 1990; B. S. Bratus, 1988; D. A. Leontyev, 2007 etc.). Being one of the highest substructures of the mental device, these values exactly and semantic orientations form the adaptation and innovative potential of the personality. At the same time according to cultural and historical psychological ideas values of the personality are determined by culture and society (E. Shpranger, 2002; E. Eriksson, 1976; A. G. Asmolov, 1990; D. A. Leontyev, 2007 etc.) . However in the conditions of modernization of traditional types of cultures the valuable and semantic reference points which earlier were determining regulation of the personality's behavior in life situations undergo a considerable transformation and devaluation. At the same time the emergence of new information opportunities, in particular in the educational environment, opens new ways for search of the best experience of overcoming the spiritual crisis which affected mankind.

One of the mechanisms of natural and seamless adoption of the best world heritage is the cross-cultural dialogue determined by culturologists as "a transnational streamflow" (T. Erikzen, 1993), "a global context" (R. Robertson, 1991), "a principle of cultural development" (A. L. Radugin, 2001) (Kravchenko, 2001; Kolesnikov, 2008). In the course of cultural dialogue borrowing and cultural diffusion take place assuming a peaceful way of transferring ideas, traditions, values and norms of life which promote progress and satisfy those requirements which the existing cultural complexes can not satisfy. Moreover, many modern researchers, after the outstanding thinkers of the XX century V. I. Vernadsky and P. Tellar de Chardenom, consider that development of humanity at domination of individualistic culture threatens the human species survival (Stefanenko, 2009). Today the positions of communitarianism are more and more affirmed approving the need of integrating individualism (respect of fundamental human rights) and collectivism (care of wellbeing of a family and society). E. Fromm (1994) called a similar ratio as the positive experience of freedom assuming selfexpression of the person in love and activity while preserving the unity with society. K. Rogers (1997) fixed a harmonious ratio between internal and behavioural tendencies in the concepts "congruence" and "a completely functioning personality". K. Young (1967) called a consistent unity of the personal and collective, that constitute a personality purpose. D. Myers defines such experience as a compromise "between individualism of the West and collectivism of the East, between egoistical independence and care, between protection of the individual rights and public well-being, between freedom and brotherhood, between I - thinking and we - thinking" (Myers, 2000).

\subsection{Ecological transformation (adaptation)}

At present the climate change awareness gained a global character. The climate changes all spheres of human life ecological psychological, social. According to a number of ecologists, at present man is not capable of stopping the climate change mechanism triggered in the biosphere any more. Sharp changes of temperature, extreme weather activity, droughts, floods, recession of agricultural productivity, a lack of pure potable water is not a complete list of the consequences of the global climate change which we are unable any more to affect. Medical, biological, social and psychological researches during the recent years show the interrelation of listed direct and indirect consequences of the anthropogenous climate change with deterioration of not only the man's physical condition, but with his mental health. In the 1960-s of the XX century in biological anthropology the direction which received the name of ecological / physiological anthropology was finally shaped up. (Selye, 1960). Problems of anthropoecology include research of adaptive variability of the human populations living in various conditions of the environment with use of anthropological methods. Interaction is considered in the person-culture-environment system (Alekseev, 1998).

A specific feature of the man is a continuous search of new adaptation forms by means of changes in the social organization and economic and cultural spheres. Very many elements of our spiritual and material culture can be 
considered as the direct adaptive features helping (or helping once) to reduce the influence of many exogenous factors. Culture (in broad understanding) is our own "human" way of adaptation to the environment, and a very mobile, dynamic way and very effective in terms of the man's survival. Environment, certainly, has an impact on cultural development. Inversely, by means of culture the man influences the habitat - he modifies it. It is possible to distinguish two adaptation levels coordinated among themselves: biological and social (non-biological). With such approach the concept "adaptation" includes actually biological changes happening on different levels of the organization of the man (individual, population, etc.) (Lamberg-Karlovsky, 1992); various adaptations on the level of non-biological systems (spiritual and material culture, individual and social behavior). The biological adaptation process of the man is in continuous interaction with changes in the cultural and social spheres, and for each specific group of the man the significance of this or that constituting element of the general process is different. Very often cultural systems smooth the environment pressure upon a human body, but they can repeatedly strengthen the existing stress or produce new types of a stress.

Adaptation degree is rather a relative feature always relating to a concrete situation. Adaptation is always concrete. The person' organism can be only more or less adapted for a concrete combination of factors in comparison with other organisms or groups, that sign which does not look adaptive at present, can become as such in other conditions of the environment, and vice versa. As a result of studying the regularity of geographical distribution of a set of anthropological signs, the concept was introduced about adaptive type of the man as a norm of biological reaction to a complex of conditions of the environment arising independently in similar conditions, and in populations which can be unrelated among themselves genetically.

\subsection{Evolution of ideas about land, community and family}

A comprehensive consideration of transformation of the personality is based on the concept of socio-natural history (Kulpin-Gubaydullin, 2008) where the man is accurately included in the system "inanimate nature - wildlife - society" and recognizes the existence of general principles and laws in this uniform system, determining the character of its functioning. Main "characters" of socio-natural history are a man who is managing and containing the landscape, an object of research - the sphere of their interaction. In focus of attention - the personality in the conditions of transition from traditional agricultural society to which certain views, traditions, relation to nature, use of rituals, submission to a natural rhythm, to an industrial and post-industrial (to information society) at the two historical stages of the XIX-XX centuries and the XX-XXI centuries are peculiar. Such more detailed transformation can be traced on the example of such quality of the personality as hardiness and process of attribution of the personality.

We will consider the three elements of tradition which first of all underwent changes. The point is about deep ideas on the basis of which human life was being formed in a traditional society. The first one out of such traditional factors which underwent change is transformation of traditional idea about the land as an immutable value. So this was throughout all history of Russia. However the XX century introduces an adjustment - the land is not in itself a value, but its opportunity to give livelihood represents a value and the very fact of possibility of working on it. During the revolution and system crisis of 1917 soldiers at the beginning of the agricultural season took a plot of land and cultivated it, hastily growing crops on seedbeds to support themselves. During World War II according to memoirs of those who were abducted to Germany for work, and then they were sent to resettlement camps, this affection for the land enabled them to survive, to keep themselves alive. People, being on a foreign territory, on the territory of the enemy, worked - and worked, generally, rather well. In a number of publications this was even a subject of criticism and was treated, nearly as the fact of treachery. But for the peasants who found themselves on the land this was simply a way to forget that they were on a foreign territory, "not to go crazy", "not to be lost". After all the land - is not simply a value, it has to be cultivated and peasants' work is one of the ways of somebody's recognition as a peasant, as a person connected with land. In the 1990-s of the XX century in the conditions of the crisis in new Russia, a part of urban population was engaged actively in vegetable gardening, having made the seasonal dachas as a way to fill up the family budget directly with the produce from the land. The beginning of the XXI century shows vast areas of Russia with neglected houses and lands.

One of the traditional peasants' symbol was community, trust the irrational in its essence. In the conditions of revolutionary crisis in the summer of 1917 when a new person came and joined the rear garrisons, according to memoirs the suntanned hands were one of the signs. Because this old peasant habit to cover arms with long sleeves, without rolling them up, is connected with a field while workers in the city on the contrary - rolled up sleeves.

Transformation of the value of kin and family. The main task of the man is to survive. For the sake of what to survive? Not only for the sake of his own surviving but also because if something happens to him, his family will live in misery and starve then. The XX century changes the value of a family and kin as units for the value of specific family members. According to the materials based on letters it is clearly evident. In one of them, a person tried to explain to his 
relatives the vision of the main objective in the war: "Now I understand that I have three grandsons, seven greatgrandsons, and, respectively, there are so many sons, and my father did not even know, how many grandsons he had. He can not call all of them by their names... My task is to protect certain people, but not the family in general ".

\section{Results and Discussions}

Ecological and biological, social and psychological markers of hardiness of the individual in the conditions of society transformation in two historical stages at the turn of the XIX-XX centuries and the XX-XXI centuries are presented in the article. The analysis and systematization of scientific approaches to a psychology problem of social competence of the personality and its harmonization, hardiness in difficult situations has been carried out. The constituents of social competence of the personality on the personal and behavioural levels have been distinguished. Major factors of the personality's adaptation in the conditions of the catching-up development of Russian society, and also psychological, traditional and historical and ecological aspects of development of the man in the conditions of the crisis era are considered. Dependence of the adaptability degree of the personality on a psychological crisis situation, historical and cultural content of a crisis stage of society development has been analysed. The main changes in understanding the outside world upon transition from the agrarian, traditional society to the urbanistic modern one have been considered. First of all, it is refusal of absolutization of ideas about the land and transformation in understanding the value of the land as mother earth. The second component of basic transformation is the transformation of the value of kin and family, formation of the personal attitude towards these categories of human life. These categories permit to understand also the attitude to nature, to analyse the initial stage of formation of ecological consciousness and as a result of the compelled change of the personality's adaptive mechanisms.

\section{Conclusion}

A similar approach to a complex retrospective study of hardiness and transformation in the conditions of both social, ecological, and cultural crisis assumes further increase of efficiency of techniques for management and correction of low level of hardiness in modern world (for children, teenagers, youth, teachers). Interdisciplinary research will allow us to determine the main components and factors, hardiness of the personality, a consequence of decrease in its level ( risk of suicides and formation of deviant behavior, regularity and dynamics of attributive processes in hardships). The study of interrelation of physical development of the population and factors of environment gives a chance to reveal risk factors of hardiness formation and adaptive capabilities of the human body among the population of a certain area for the purpose of working out recommendations on their health promotion. In practice such view of hardiness can be applied for developing adaptation technologies and techniques that can be used in training migrants who face cultural, psychological, ecological, social measurements of the host society.

\section{Recommendations}

Research results will help to determine the main components and factors characterizing the personality's hardiness, consequences of decrease in its level (risk of suicides and formation of deviant behavior, regularity and dynamics of attributive processes in hardships). Results of this research will give a person the chance to solve effectively hardship problems at the expense of the biological, psychological resources mediated by cultural and historical factors. The study of interrelation of physical development of the population and factors of the environment will give the possibility to reveal risk factors of hardiness formation and adaptive abilities of the body in people of a concrete area for the purpose of working out recommendations on their health promotion. The developed adaptation technologies and techniques can be applied in training migrants who face cultural, psychological, ecological, social measurements of the host society. Research results are of great importance in advisory and psychotherapeutic activity.

\section{References}

A manual on water resources and adaptation to climate change (2009). The convention on protection and use of transborder streams and international lakes: Materials of the European economic commission. - Geneva, UN.

Alekseyev, V.P. (1998). Essays of ecology of the man. - Moscow.

Asmolov, A.G. (1990). Personality Psychology. - Moscow: Izd. University Press.

Eriksen, T. H. (1993). Ethnicity and Nationalism. Anthropological Perspective. - London: Pluto Press. 
Fromm, E. (1994). Anatomy of Human Destructiveness. - Moscow.

Gregory, B. (1972). Steps to an Ecology of Mind. - New York: Ballantine.

Heidegger, M. (1960). Sein und Zeit. - Tubingen.

Hobsbawm, E. \& Terence, R. (1983). The Invention of Tradition. - Cambridge, England: Cambridge University Press. http://dx.doi.org /10.1017/CBO9781107295636

Jackson, P. (2001). Introduction to Expert Systems (3rd ed). - Moscow: Williams.

Kolesnikov, A.S. (2008). Intercultural philosophy in education. Comparative vision of history of philosophy. - St. Petersburg.

Kravchenko, A. I. (2001). Cultural science. - Moscow: Academic project.

Kulpin-Gubaydullin, E.S. (2008). The Seven-generation cycles of Russian history. Problems of mathematical history. Bases, information resources, analysis of data. Moscow: LKI/URSS publishing house.

Lamberg-Karlovski, K. \& Sablov, J. (1992). Ancient civilizations: Middle East and Mesoamerica. Moscow

Leontyev, D. A., Rasskazova E. I. (2006). Test of hardiness. Moscow: Sense.

Maddi, S. R., \& Khoshaba, D. M. (1994). Hardiness and mental health. Journal of Personality Assessment. http://dx.doi.org/10.1207/ s15327752jpa6302_6

Maslow, A. (1968). Toward a psychology of being 2. ed. - New York : Van Nostrand Reinhold co. http://dx.doi.org/10.1037/10793-000

Mikhalina, O. A (2009). Education Philosophy of the West and East: need of developing a cross-cultural dialogue. Culturologist's analytics. 3(15) from http://www.analiculturolog.ru/journal/archive/item/352-article_44-6.html

Milov, L.V. (1992). Climatic factor and features of the Russian historical process. History issues, 4-5.

Myasischev, V.N. (1960). Personality and neuroses. - Leningrad: Publishing house of Leningrad university

Myers, D. (2000). Social psychology. Intensive course. St-Petersburg.

Rasskazova, E. I. (2006). Psychological concepts of stress and its consequences. Psychology of mental states. Kazan. The V-th issue.

Richard, T. (1991). Passion of Western Mind

Robertson, R. (1992). Glocalization. Social theory and global culture. - London, Sage. http://dx.doi.org/10.4135/9781446280447

Selye G. (1960). Essays of adaptation syndrome. - Moscow .

Shapovalov, V. F. (2003). Sources and sense of the Russian civilization. - Moscow: Fair-Press.

Shpet, G. (1989). An essay of development of Russian philosophy. Writings. - Moscow.

Solovyov, V.S. (1912). Some words in protection of Peter the Great. Collected works (2nd ed.). - St-Petersburg.

Special report of the IPCC working group II, (1997). Climate change consequences for regions. Assessment of vulnerability, from http://www.archipelag.ru/agenda/geoklimat/history/consequences.

Stefanenko, T. G. (2009). Ethnopsychology (4th ed.). Moscow: Aspect Press

Toffler, A. (2002). Future shock. - Moscow : ACT publishing house. 